\title{
On the Acquisition of Final Voiced Stops*
}

\author{
Eve V. Clark
}

Stanford University

Stanford, California

and

\section{Melissa Bowerman}

\author{
Max Planck Institute for Psycholinguistics \\ Nijmegen
}

Children recognize many distinctions among the linguistic sounds they hear long before they are able to produce them (e.g., Dodd 1975, Maccoby \& Bee 1965, N.Smith 1973). They may recognize the difference between dog and doll yet pronounce both [do]. One problem they have to solve is how to deal with this discrepancy. How should they produce the contrasts they perceive when they have not yet mastered the adult techniques for doing so? At first they simply don't try to produce certain contrasts. Their words typically lack final consonants ([do] for dog), unstressed syllables ([wei] for away), and clusters ([t] for stick), as well as many other segments present in the adult versions (see Ferguson \& Farwell 1975, Kiparsky \& Menn 1977, Macken 1979, Menn 1976, N.Smith 1973). Later, although they may try to produce more of the contrasts they perceive, they often lack the skills necessary to make these match the adult targets. Yet erroneous productions may reveal that they have analyzed certain contrasts even when they don't produce them. The problem children have to solve is how to align what they can produce with what they already perceive. 
In this paper, we consider one particular problem and how children solve it: the perception and production of final voiced consonants. Children usually begin by omitting all final consonants, as in [do] for dog, [b] for fish, etc. Once they start attempting final consonants, they typically master nasals and voiceless stops first and voiced stops later. Moon becomes [mun], and stick [ttk], while dog remains [do]. Some children omit all final voiced stops; others replace them with voiceless stops at the same place of articulation, e.g., a final $[t]$ in place of [d], with concomitant lengthening of the vowel, so mat [mæt] contrasts with mad [mæit] (Velten 1943, N. Smith 1973; see also Hooper 1977). These alternatives are summarized in (1):

Adult targets

Child forms

$\begin{array}{lllllllll}\mathbf{m} & \mathbf{n} & \mathbf{n} & \mathbf{m} & \mathbf{n} & \mathbf{y} & \mathbf{m} & \mathbf{n} & \mathbf{n} \\ \mathbf{p} & \mathbf{t} & \mathbf{k} & \mathbf{p} & \mathbf{t} & \mathbf{k} & \mathbf{p} & \mathbf{t} & \mathbf{k} \\ \mathbf{b} & \mathbf{d} & \mathbf{g} & - & - & - & \mathbf{p} & \mathbf{t} & \mathbf{k} \\ \text { Other } & & - & - & - & - & - & -\end{array}$

These strategies show that children have identified the nasals and voiceless stops as being in contrast with each other, and as contrasting with zero, or, perhaps, with voiced final stops. When children substitute $/ \mathrm{k} /$ for $/ \mathrm{g} /$ in big, for example, we have overt evidence that they have correctly identified the appropriate place of articulation. But evidence that they are aware of voicing at this stage is typically indirect: Children first produce voiceless stops appropriately in words like stick or cat but continue to omit voiced ones in words like big or mad; then they begin to produce voiceless ones in place of voiced ones as well, e.g., [bik], [mæt]. Voiceless substitutes for voiced stops, then, only emerge after appearing, appropriately, in target words with voiceless stops.

In this paper, we document, for two children, an intermediate stage that gives direct evidence that they have analyzed both voicing and place of articulation in final voiced stops. The path these children followed at first was typical. The first final consonants they produced appropriately were the (voiced) nasals [m], [n], and [n] (in words like boom, moon, and sing), followed shortly by the voiceless stops [p], [t], and [k] (in words like hop, bite, and stick). At this point, final voiced stops, as in bib, kid, or rug, were simply omitted. But then, for some months, the three voiced stops in final position ([b], [d], and [g] in adult 
targets) were systematically replaced by their homorganic nasals, often with a following voiceless stop at the same place of articulation, [mp] for [b], [nt] for [d], and [nk] for [g]. These contrast with target final nasals because of the voiceless release, a voiceless stop at the same point of articulation. We will call this approach, shown in the third row of (2), the "nasal strategy":

Adult targets

Child forms

$\begin{array}{llllll}\mathbf{m} & \mathbf{n} & \mathbf{n} & \mathbf{m} & \mathbf{n} & \mathbf{y} \\ \mathbf{p} & \mathbf{t} & \mathbf{k} & \mathbf{p} & \mathbf{t} & \mathbf{k} \\ \mathbf{b} & \mathbf{d} & \mathbf{g} & \mathbf{m}(\mathbf{p}) & \mathbf{n}(\mathrm{t}) & \mathbf{y}(\mathbf{k})\end{array}$

From these data, we will argue that these two children had analyzed final stops at this point in terms of (a) place of articulation, and (b) voicing. They relied on nasal consonants because they had already mastered the production of nasals in both initial and final position, at all three places of articulation - labial, alveolar, and velar. The evidence for such an analysis, we argue, is much more direct with such a nasal strategy than it is with either omissions alone or substitutions of the equivalent voiceless stop for a final voiced stop. Finally, we suggest that reliance on a nasal strategy is closely linked to the articulatory difficulty of producing final voiced stops.

\section{The Data}

Our data are drawn from the spontaneous speech of Damon and Eva, recorded in detailed longitudinal notes by the first and second authors respectively. These notes were kept on a daily basis and supplemented by some tape-recordings. Both D and E were acquiring English as their first language.

D's data ${ }^{1}$ can be divided into three periods, the first characterized by mastery of final nasals and voiceless stops, the second by use of the nasal strategy, and the third by mastery of final voiced stops. During Period 1, D had mastered his first final consonants, the three nasals, [m], [n], and [n], and went on to master the three voiceless stops, [p], [t], and [k]. Both classes of sounds were produced where they were called for in target words. In targets ending in [b], [d], or [g], however, D omitted the stops altogether. This is summarized in (3): 
(3)

\begin{tabular}{llllll}
\multicolumn{3}{c}{ Adult targets } & \multicolumn{3}{c}{ D's forms } \\
$\mathbf{m}$ & $\mathbf{n}$ & $\mathbf{n}$ & $\mathbf{m}$ & $\mathbf{n}$ & $\mathbf{g}$ \\
$\mathbf{p}$ & $\mathbf{t}$ & $\mathbf{k}$ & $\mathbf{p}$ & $\mathbf{t}$ & $\mathbf{k}$ \\
$\mathbf{b}$ & $\mathbf{d}$ & $\mathbf{g}$ & - & - & -
\end{tabular}

D already had a voiced/voiceless contrast in initial position by this time. This period covered about two months, roughly from age $1 ; 6$ to $1 ; 8$.

During Period 2, D applied the nasal strategy to all target words ending in [b], [d], and [g]. The outcome of this strategy is summarized in (4):

(4)

Adult targets

D's forms

$\begin{array}{llllll}b & d & g & m(p) & n(t) & \mathbf{y}(k)\end{array}$

This period lasted from age $1 ; 8,1$ to $1 ; 10,14$, the last point at which $D$ was observed using this strategy. During this period, D applied the nasal strategy to 33 word-types whose adult versions contained final voiced stops. The inventory of forms used, the child's age at each observation, ${ }^{2}$ and the point of eventual adult-like production, are listed in Appendix 1. During this period, D was also unobtrusively tape-recorded several times when he was spontaneously producing words that should have ended in [b], [d], or [g] (e. g., in naming pictures in a Richard Scarry book). Target words on these tapes provided a more permanent record against which to check on-the-spot transcriptions. Instances of about $50 \%$ of the types observed were checked this way, and showed no discrepancies with the forms noted in the daily observations.

In Period 3, D replaced final nasals with the appropriate voiced stops in all the target words that should have contained [b], [d], or [g]. At this point, $D$ also began to produce final liquids, $[1]$ and $[r]$, and final voiced and voiceless fricatives, [v], [z], and [s]. His inventory of final consonants just before his second birthday is summarized in (5):

\section{Adult targets D's forms}

$\begin{array}{llllll}\mathbf{m} & \mathbf{n} & \mathbf{y} & \mathbf{m} & \mathbf{n} & \mathbf{y} \\ \mathbf{p} & \mathbf{t} & \mathbf{k} & \mathbf{p} & \mathbf{t} & \mathbf{k} \\ \mathbf{b} & \mathbf{d} & \mathbf{g} & \mathbf{b} & \mathbf{d} & \mathbf{g} \\ & \mathbf{l r} & & & \mathbf{l r} & \\ \mathbf{v} & \text { zs } & & \mathbf{v} & \text { zs } & \end{array}$


Our next set of data is drawn from the extensive daily notes made by the second author in her diary record of $E .^{3}$ These notes were supplemented by annotated summaries of E's vocabulary made every two weeks, ${ }^{4}$ and by occasional tapes. About one sixth of the target words observed in E's speech were recorded. These forms were all in accord with the on-the-spot transcripts. E's data are also divided into three periods. The first, from about $1 ; 3$ to 1;6, covers the months when $E$ began to make appropriate use of both final nasals and voiceless stops. ${ }^{5}$ The second covers the period when she applied the nasal strategy to all target words ending in $[\mathrm{b}],[\mathrm{d}]$, and $[\mathrm{g}]$. This lasted from $1 ; 5,14$ to at least $1 ; 10,27$, with examples of some forms noted up to age $2 ; 0,5$. During Period 2, E applied the nasal strategy to 37 word-types where the adult target contained a final voiced stop. All the pertinent words and the forms observed are listed in Appendix 2. The point of onset of E's third period, when the nasal strategy was replaced by production of the appropriate final voiced stops was not documented since phonetic notations in the diary were virtually discontinued after about 1;10,7.

The corpora of forms from the two children are very similar. They used a similar number of pertinent word-types, and much the same range of tokens. There was also considerable overlap in many of the words produced (compare Appendices 1 and 2).

\section{Damon}

Final nasals: By the end of Period 1, D typically produced final nasals wherever adult targets called for them, and in monosyllabic words produced the nasal at the appropriate place of articulation, e.g., [m] in room, vroom, cream, comb, and swim; [n] in plane, down, (ma)chine, gone, raisin, spoon, mine, and all done; and [n] in swimming, raining, crying, ring, and string. (Velar [ $\mathrm{n}$ ] became more frequent during this period with -ing on verbs.) In two words, though, both long established in his lexicon, $D$ persisted in using consonant harmony, often producing final [m] instead of [n], as in man, which alternated between [mæm] and [mæn], and cushion, usually [bəbum] (see N. Smith 1973).

From Period 1 onwards, D also produced several words with target nasal + stop clusters in final position. Those in which the nasal was followed by a voiceless stop were labial jump; alveolar ant, don't, aunt, and won't; and velar drink, bank, pink, and sink. The labials fluctuated 
throughout Period 2 between [-m] and [-mp]. The alveolars consistently appeared as [-n]. And all the velar clusters appeared appropriately as [-nk]. This distribution of voiceless stops following a nasal parallels the use of voiceless releases in D's application of the nasal strategy during Period 2 (see Appendix 1). ${ }^{6}$

Final voiceless stops: During Period 1 (from 1;6,24 to 1;8,7), D also began to use final voiceless stops. These were established gradually at all three places of articulation: [p] appeared in $u p(1 ; 6,24)$, sleep $(1 ; 7,2)$, top $(1 ; 7,9)$, and cup $(1 ; 7,14) ;[t]$ was produced first as a glottal stop but during this month appeared as final $[t]$ in shut $(1 ; 7,0)$, carrot $(1 ; 7,2)$, float $(1 ; 7,7)$, blanket $(1 ; 7,9)$, nut $(1 ; 7,14)$, put $(1 ; 7,14)$, out $(1 ; 7,16)$, hit $(1 ; 7,29)$, and bite $(1 ; 8,5)$. Several words continued to be produced with a final glottal stop in place of [t], e.g., get $(1 ; 7,7)$, wet $(1 ; 7,7)$, boat $(1 ; 7,9)$, eat $(1 ; 7,21)$, and cart $(1 ; 7,23)$, but from $1 ; 8$ or so, new monosyllabic words containing a final voiceless alveolar were typically produced with final $[\mathrm{t}]$. Before final $[\mathrm{k}]$ emerged as $[\mathrm{k}]$, it too appeared as a glottal stop in some words. But final [k] was already established in many words at the start of this period and appeared, for example, in bike $(1 ; 7,0)$, stuck $(1 ; 7,0)$, back $(1 ; 7,2)$, cork $(1 ; 7,7)$, book $(1 ; 7,7)$, duck $(1 ; 7,8)$, fork $(1 ; 7,21)$, broke $(1 ; 7,23)$, milk $(1 ; 7,23)$, truck $(1 ; 7,28)$, snake $(1 ; 8,7)$, and stick $(1 ; 8,8)$.

Omission of final voiced stops: During the same period, D consistently omitted final voiced stops. To give just a few examples, Herb was pronounced [ha] $(1 ; 6,24)$, food [fu:] $(1 ; 7,0), \operatorname{dog}$ [do] $(1 ; 7,1)$, bird [b3] $(1 ; 7,2)$, need [ni] $(1 ; 7,7)$, bed $[\mathrm{b} \varepsilon](1 ; 7,8)$, leg $[1 \varepsilon](1 ; 7,16)$, bib $[\mathrm{bl}](1 ; 7,23)$, outside [awtsai] $(1 ; 7,29)$, road [row] $(1 ; 8,14)$, knob [no] $(1 ; 8,14)$, and read [ri] $(1 ; 8,15)$. At no point during this period did $D$ use either a glottal stop or a voiceless stop in final position in words requiring a voiced stop.

The Nasal Strategy: In D's speech, the nasal strategy appeared to be systematic by place of articulation. At first, he added the velar nasal [y] (normally followed by [k]) only to target words in final [g]. Thus, the first 11 words he applied the nasal strategy to were rug [rAnk] $(1 ; 8,1)$,

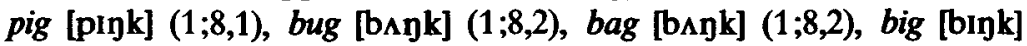

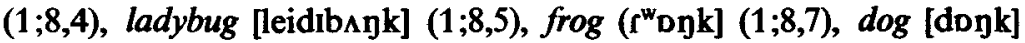

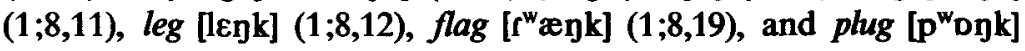
$(1 ; 8,19)$. So in the space of two and a half weeks, he used [n] in a number of established and new words in his vocabulary. Some words that had long been in his vocabulary alternated between their older forms and the new nasal forms. ${ }^{7}$ For instance, dog was usually produced as [dD], and was only observed twice as [donk] $(1 ; 8,11 / 1 ; 8,22)$. Most 
words, though, were used consistently with final [n]. New words acquired during this nasal period entered immediately with [nk] in

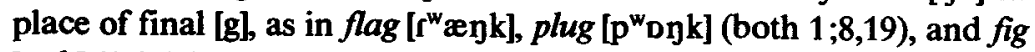
[fink] $(1 ; 9,14)$.

Once he had amassed a number of words in [ $[(k)]$, D began to add nasals to words that ended in labials and alveolars as well. His first were $B o b$ [bom/bomp] $(1 ; 8,19), b i b[\mathrm{bIm}](1 ; 8,21),{ }^{8}$ and $s c a b\left[\mathrm{k}^{\circ} æ \mathrm{~m}\right]$ $(1 ; 8,21)$, followed by rhubarb [ruba:m] $(1 ; 8,23)$, and tub $[\mathrm{t} \Lambda \mathrm{m}](1 ; 8,26)$ in the same week. Knob followed a week later, [nom] $(1 ; 9,0)$, and one well established word, Herb, alternated a couple of times in the following month between its usual form, [h3], and a nasal form [h3m] $(1 ; 9,23 / 1 ; 9,28)$.

The first alveolar [d] forms $D$ replaced by nasals did not appear until three weeks after the onset of the nasal strategy. At first, they were assimilated to the labial class with final [m] rather than [n], e.g., God [gom], lid [jlm], sled [sєm/sjem] (all 1;8,22), bed [bem], cupboard [kægum] (both 1;8,23). In the next few days, lid shifted to [jin] $(1 ; 8,25)$, but the next few final alveolars were still produced with [m] rather than [n]: $\operatorname{Rod}$ [rom], red [rem] (both $1 ; 8,29)$, road [rowm] $(1 ; 9,0)$, and read [rim] $(1 ; 9,5)$. A week later, D began to use [n] more consistently on words ending in a final voiced alveolar: bird was produced as [b3n] $(1 ; 9,13)$, and, in the next week, word emerged as [w3n] $(1 ; 9,14)$ and wood as [won] $(1 ; 9,21)$. Overall, then, words ending in [d] were among the last to which $D$ applied the nasal strategy.

Finally, D applied the nasal strategy on a very few occasions when he was attempting to produce other final voiced segments. He had begun to produce plural $-s$ on nouns, and on one occasion produced the form toes as [town] $(1 ; 10,9)$, with the final voiced allomorph replaced by a nasal at the same point of articulation. Swimming pool, originally [wiminpu], also appeared during this period with a final nasal, [wImInpun] $(1 ; 9,23 / 1 ; 10,7)$. A couple of months later, the nasal was replaced by the appropriate liquid, [wiminpul] $(2 ; 0,9)$, and roll was produced as [rown] $(1 ; 11,4)$ but repaired immediately to [rowl]. Final /1/ and $/ \mathrm{r} /$ both began to appear from $1 ; 9-1 ; 10$ onwards. The appropriate final liquids in ball, door, floor, doll, wheel, sore, stool, hole, bowl, fall, fell, towel, tickle, bottle, more, water, car, cereal, racquetball, roll, full, table, sugar, and shower all emerged between 1;9,15 and 1;11,18.

Replacing nasals with voiced stops: In Period 3, just over two months after the introduction of the nasal strategy, D produced his first final [g], in $\operatorname{dog}(1 ; 10,14)$. This was followed a few days later, in rapid succession, by $[\mathrm{g}]$ in bug $(1 ; 10,16)$, rug $(1 ; 10,17)$, big $(1 ; 10,19)$, 
with occasional lapses back to the nasal form, ${ }^{9}$ ladybug $(1 ; 10,19)$, plug $(1 ; 10,19)$, bag $(1 ; 10,21)$, frog $(1 ; 10,22)$, and flag $(1 ; 10,28)$. From this point on, any residual uses of a final nasal form were promptly repaired to the target voiced stop, [g]. Only one new word, fig, entered his vocabulary after this with final $[\mathrm{gk}]$ instead of $[\mathrm{g}]$.

The first [b] in final position appeared at much the same time, in Herb $(1 ; 10,13)$, followed six days later by $B o b(1 ; 10,19)$. (Both names were frequent in D's speech, and while Herb only occasionally appeared with a final nasal, Bob had been [bomp] for several weeks.) From this point on, $D$ used only final [b] in these two names. In the next week or so, he also used a final [b] with $b i b(1 ; 10,23)$, crab $(1 ; 10,25)$, and $\operatorname{scab}(1 ; 10,28)$. That is, having got one final $[b]$, the rest of his words with a final [b] quickly followed - just as they had for the velars - over the relatively short space of two weeks.

D's first final [d] appeared during the same period, in a newly acquired word, cloud [kawd] $(1 ; 10,21)$. Two days later, he produced bed as [bed] $(1 ; 10,23)$, and four days after that bird as [b3d] $(1 ; 10,27)$. In the next month, his remaining uses of final [n] for [d] all shifted to [d]: read [rid] $(1 ; 11,5)$, lid [lid] $(1 ; 11,10)$, red repaired from [ren] to [red] $(1 ; 11,11)$ with [red] becoming the only form from then on, and road [rowd] $(1 ; 11,17)$. From this point on, all new words acquired were produced with the appropriate final [d]. Also, a few words with final [d] to which the nasal strategy had not been applied, e.g., outside [awtsai], bread $\left[b^{w} \varepsilon\right]$, from now on appeared with final [d]: [awtsaid], [ $\left.b^{w} \varepsilon d\right]$.

\section{Eva}

Final nasals: In Period 1, before E's first uses of the nasal strategy, she too used final [m] in words like come $(1 ; 4,3)$, gum $(1 ; 4,15)$, and home $(1 ; 4,21)$; final $[\mathrm{n}]$ in $\operatorname{chin}(1 ; 3,2)$, moon $(1 ; 3,26)$, on $(1 ; 4,3)$, skin $(1 ; 4,11)$, again $(1 ; 4,18)$, done $(1 ; 4,19)$, and run $(1 ; 4,28)$; and final $[\mathrm{y}]$ in ding (the noise of a windbell) $(1 ; 4,9)$. In many words calling for [n] or [n], though, E produced only [m], e.g., moon [muwm] $(1 ; 4,2)$, man [mæm] $(1 ; 4,4)$, down [dəm] $(1 ; 4,6)$, balloon [byæm] $(1 ; 4,9)$, swing [byæm] $(1 ; 4,18)$, and bang [bæm] $(1 ; 4,27)$, as a result of consonant harmony (see N.Smith 1973). Over the next two months, however, she made increasing use of the appropriate final nasals.

From the end of Period 1 onwards, E also produced nasal +stop 
clusters appropriately in final position: final $[-\eta \mathrm{k}]$ in thank, drink, and bonk; [-nt] in plant, don't and pants, and [-mp] in jump. As in D's case, the distribution of her voiceless stops after nasals in such final clusters paralleled her uses of a voiceless release in the nasal strategy. ${ }^{10}$

Final voiceless stops: During the same period, E began to use final voiceless stops at all three places of articulation. Final [p] now appeared consistently in words like up $(1 ; 4,18), \operatorname{cup}(1 ; 4,21)$, soap $(1 ; 4,23)$, drip $(1 ; 5,1)$, wipe $(1 ; 5,6)$, tape $(1 ; 5,11)$ pop $(1 ; 5,13)$, and soup $(1 ; 5,14)$. Final [t] appeared in such words as hot $(1 ; 4,13)$, got $(1 ; 4,18)$, hat $(1 ; 4,19)$, coat $(1 ; 4,20)$, wet $(1 ; 4,20)$, and bite $(1 ; 4,22)$. And final $[k]$ appeared in coke $(1 ; 3,18)$, clock $(1 ; 3,25)$, sock $(1 ; 4,13)$, yuck $(1 ; 4,18)$, back $(1 ; 4,21)$, block $(1 ; 4,24)$, book $(1 ; 4,24)$, milk $(1 ; 4,27)$, cake $(1 ; 5,10)$, rock $(1 ; 5,11)$, walk $(1 ; 5,14)$, and look $(1 ; 5,16)$.

Omission of final voiced stops: During Period 1, E consistently omitted final voiced stops. For example, bird was produced as [bi] $(1 ; 3,2 / 1 ; 4,15 / 1 ; 4,19)$, bread as [byæ] $(1 ; 4,19)$, slide as [dæy] $(1 ; 5,1)$, seed as [di] $(1 ; 5,6)$. E did produce final stops on three words with target voiced stops: In one, cold, she produced a voiced alveolar stop, [gowd] $(1 ; 4,23)$, but it's not clear whether she continued to produce this word in this form. In the second, bead, she produced a voiceless final stop, [bitt], on at least three occasions $(1 ; 4,23 / 1 ; 5,8 / 1 ; 5,9)$. In the third, big, she also produced a voiceless final stop, [bik] $(1 ; 5,14 / 1 ; 5,15)$. These appear to have been E's only attempts in Period 1 at a final consonant in words calling for a voiced stop. All others were produced with no final stop at all.

The Nasal Strategy: At 1;5,14, E began using the nasal strategy and, unlike $D$, applied it from the start to all three places of articulation. She used it first in a word with a final [g], producing egg as [æ]k] $(1 ; 5,14)$. She continued to produce egg in this form for at least the next five months (to $1 ; 10,27)$ and possibly longer. In the next two weeks, $E$ produced [n] in hot-dog [-dayk] $(1 ; 5,16)$, frog [on] $(1 ; 5,18)$, and bag [bænk] $(1 ; 5,20)$. She produced [n] in seed [dint] $(1 ; 5,15)$, bed [bæn] $(1 ; 5,30)$, and good [gun] $(1 ; 5,30)$. Both the velar and alveolar nasals were normally followed by a voiceless release, $[k]$ and $[t]$ respectively. $E$ also used [m] in $b i b[\mathrm{bim}](1 ; 5,29)$. During the next month, she added final nasals to another word with a final $[\mathrm{g}]$, pig $[\mathrm{bink}](1 ; 6,4)$, and to nine more with final [d], food [bun] $(1 ; 6,5(\mathrm{I}))$, bead [bin] $(1 ; 6,0-1 ; 6,14)$, mad [mæ:n] $(1 ; 6,18(\mathrm{I}))$, did [din] $(1 ; 6,21)$, (out)side [dayn] $(1 ; 6,29)$, kids [gins] $(1 ; 6,27)$, Brad [bæn] $(1 ; 6,28)$, dead [dænt] $(1 ; 7,0)$, and slide [dæyn] $(1 ; 6,15-1 ; 7,0)$. E continued to apply the nasal strategy at least until $1 ; 10,27$. 
E also briefly applied the nasal strategy to an intervocalic [g] as well. Eggy took the form [æฤki] $(1 ; 4,17)$. But other diminutives like doggie, buggie, froggie, and birdie, all appeared with a medial voiced stop. Tiger did appear once with an inserted medial nasal, followed by a voiced stop, [tayngi] $(1 ; 7,2)$, immediately after an adult utterance of the word. And so did wagon: [bæuki] $(1 ; 7,16)$, again in imitation. ${ }^{11} \mathrm{E}$ also produced some medial voiced or flapped targets with medial nasals instead, e.g., I did as [andin] $(1 ; 6,21)$, naughty as [nani] $(1 ; 7,4)$ then [nadi] $(1 ; 7,8)$ (also corrected from [nani] to [nadi] in imitation of an adult at $1 ; 7,17)$, noodle as [nuni] $(1 ; 8,9)$, hiding as [aynin] $(1 ; 10,27)$, put it in as [pun in i:n] $(1 ; 10,28)$, and putting as [punin] $(2 ; 0,15) .12$

E's reliance on the nasal strategy appeared to affect other parts of her phonology as well, notably words with medial nasals. Tummy appeared as [tampi] $(1 ; 5,24(\mathrm{I}))$, then as $[$ dambi] $(1 ; 6,9 / 1 ; 6,16 / 1 ; 7,0) ;$ fan$n y$ was produced as [bændi] $(1 ; 6,6(\mathrm{I}) / 1 ; 6,15)$, then [bænti] $(1 ; 7,8)$, all cleany as [angindi] $(1 ; 6,14(1))$, Jennies as [dændis] $(1 ; 6,16(1) / 1 ; 7,29)$, funny as [bændi] $(1 ; 6,18)$, tiny as [dayndi] $(1 ; 6,27(1) / 1 ; 7,1)$, dinner as [dindi] $(1 ; 6,30(I))$, boney as [bondi] $(1 ; 7,0(I))$, panny as [pænti] $(1 ; 7,6)$, comby as [gombi] $(1 ; 7,6(\mathrm{I}))$, Kimmy as [gimbi] $(1 ; 7,6(\mathrm{I}))$, tennis as [tændis] $(1 ; 7,6)$, doughnut (earlier [dawndi] $(1 ; 7,5(\mathrm{I}))$ as [dondit] $(1 ; 7,18(\mathrm{I}) / 1 ; 7,25 / 1 ; 8,3 / 1 ; 8,17)$, dummy as [dambi] $(1 ; 7,18)$, spinach as [bindi] $(1 ; 7,21(\mathrm{I}))$, and brownie as [bawndi] $(1 ; 8,0(\mathrm{I}))$. Interestingly, other words like mommy or Nanny (grandmother) were never produced with an inserted stop after the medial nasal. ${ }^{13}$

According to the summary notes, $\mathrm{E}$ was still applying the nasal strategy most of the time at $1 ; 10,7$. But there is a slight indication from a month earlier that she was trying to produce final stops, still not fully voiced but in clear contrast to her heavily aspirated final voiceless stops, with bead as [bi: $\left.{ }^{\circ}\right](1 ; 8,27)$, kids as [gits] $(1 ; 8,28)$, and eggs as [yæks] $(1 ; 8,28)$. She also produced big as [bik] $(1 ; 9,5)$, and tried a target nasal + voiced stop combination two days after that, with hands as [ænts] $(1 ; 9,7)$ instead of her usual final nasal.

\section{Discussion}

These data show two things. First, the two children produced final voiced stops only after they mastered final nasals and voiceless stops. Second, they mastered final voiced stops only after applying the nasal strategy to them. Why should final voiced stops be difficult for children to produce? And why did these children rely on a nasal strategy? 
In producing a final voiced stop, the speaker must maintain voicing during closure. To do this requires enough subglottal air pressure to keep up the voicing until the stop closure is released (Slis 1970, Smith \& Westbury 1975). In a study of adults, final voiced stops were partly devoiced as often as $50 \%$ of the time. That is, voicing lasted only for the first two-thirds of the stop duration (B. Smith 1979). Children in the same study partially devoiced their final stops $98 \%$ of the time, maintaining voicing for only the first third of the stop duration, that is, for only half the interval, proportionately, that adults did. Since both the two- and four-year-olds studied were producing target voiced stops, Smith's findings suggest that the difficulty younger children experience stems from their inability to maintain voicing in final stops.

Children resolve this difficulty in different ways: They may wait until they can maintain some degree of voicing before adding in the appropriate voiced stops. Alternatively, they may try to produce voiced stops but fail. These failures have been interpreted in one of two ways. Some observers have suggested that children were simply substituting a voiceless stop for the voiced one. Others have postulated a phonological process of devoicing that is applied to all stops in final position. ${ }^{14}$ Yet another alternative is that children may contrast voiced with voiceless final stops by producing longer vowels before what should be voiced stops (Velten 1943, Hooper 1977). ${ }^{15}$

Our study documents yet another solution children apply when they cannot yet maintain sufficient subglottal pressure to produce and prolong voicing in final stops. Both Damon and Eva produced the nasals homorganic with the target voiced stops, often with a devoiced nasal release (as in pig said as [pink]). Both children already contrasted different points of articulation for final voiceless stops (e.g., cup, out, book) and could also produce two or more different nasals in final position (e.g., swim, plane, ring). Since nasals are produced with closure at the point of articulation with simultaneous voicing, the nasal strategy allowed the children to mark both place of articulation and voicing at the point where their adult targets required final voiced stops. Both Damon and Eva relied on this strategy for several months. The open velum allowed free passage of air from the lungs, so they could maintain the voicing needed for the contrast with final voiceless stops (as in bag versus back:[bænk], [bæk]). At the same time, the non-nasal, voiceless release marked such forms as being in contrast with target nasals in words like boom, man, or ring.

These two children are not unique in adopting a nasal strategy. A child called Lasan, described by Fey and Gandour (1982), produced 
all his final voiced stops from $1 ; 9$ to $2 ; 1$ with a nasal release. That is, when he produced words ending in a voiced stop, he consistently followed the stop with a homorganic nasal. He produced light bulb as [jajt thabm], bead as [bidn], and big as [bign]. He treated new (nonsense) words introduced during this period like other words ending in voiced stops: each final voiced stop was consistently followed by a nasal. Fey and Gandour argued that Lasan's motivation here was to establish a contrast between final voiceless and voiced stops. We suggest further that Lasan adopted his strategy for the same reason that Damon and Eva adopted theirs. Both strategies allowed the children to voice their final stops. ${ }^{16}$ In applying their nasal strategies, all three children made use of resources already mastered. And they made use of them to mark surface contrasts before they could produce the target segments appropriately (see also Ingram 1975). That is, they used old means to solve a new problem.

The consistent maintenance of both voicing and place of articulation in D's and E's nasal strategy is strong evidence that they had analyzed the contrasts between voiced and voiceless stops at different points of articulation before they could produce them. This differentiation of voiced and voiceless stops is further backed by the children's contrasts between target final nasals and voiced stops: the latter were often followed by a non-nasal, voiceless release; the former never were. In comprehension, these children had clearly perceived and identified the dimensions of the contrasts in question. In production, they relied on their nasal strategy to make the necessary contrasts, as shown in (6):

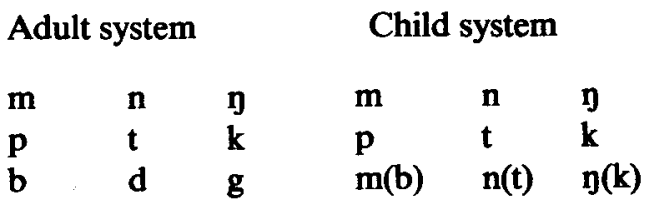

If the analysis of the nasal strategy we have offered is correct, we have evidence that children unable to produce final voiced stops have nevertheless analyzed and represented them appropriately. The appropriateness of the representation is further supported by the rapid replacement, during Period 3, of D's nasal + stop combinations by the appropriate voiced stops: final $[\mathrm{m}(\mathrm{p})]$ went to $[\mathrm{b}],[\mathrm{n}(\mathrm{t})]$ to $[\mathrm{d}]$, and $[\mathrm{g}(\mathrm{k})]$ to [g] within two to three weeks. Children, then, perceive dimensions of contrasts they cannot yet produce. And they are ingenious at finding 
strategies to realize such forms in production when they are still unable to produce them.

\section{Acknowledgements}

* Preparation of this paper was supported in part by a grant from the National Institutes of Child Health \& Human Development (1-R01HD18908-01). We are grateful to Ruth A. Berman, Herbert H.Clark, Marlys A. Macken, and Marilyn M. Vihman for commenting on an earlier draft, and to our respective children, Damon and Eva, for providing the data we discuss here.

Requests for reprints can be addressed to Eve V.Clark, Department of Linguistics, Stanford University, Stanford, California 94305, U.S. A., or Melissa Bowerman, Max Planck Institute for Psycholinguistics, Berg en Dalseweg 79, 6522 BC Nijmegen, The Netherlands.

\section{Footnotes}

1 Damon, son of the first author, is an only child growing up in northern California. His exposure to English at this point was from his father who spoke a standard mountain-west US English, and his mother who spoke British English (RP, slightly modified by eleven years in the US). During the months under study, $D$ produced an increasing number of word combinations (with an upper range of six to eight words), and his first grammatical morphemes, - ing, plural $-s$, and occasional irregular and regular past tense forms.

2 Ages are given in years, months, and days.

3 Eva is the younger of the second author's two children. Her main exposure to English had been from her parents who both spoke a standard central US English, and a caretaker who spoke a midwest (Kansas) variety of US English. During the period under study, $E$ at first produced mainly one word at a time, but within a couple of months produced an increasing number of two-word combinations and her first grammatical morphemes, plural $-s$ and -ing (around 1;9). By 1;8 to 1;9, her utterances had increased in length, for an upper bound of about six words.

4 The summaries occasionally contained forms not noted separately in the daily records. Examples cited only in the summaries are listed in Appendix 2 with the appropriate double dates, e.g., 1;6,0-1;6,14.

5 Unlike D, E had no voiced/voiceless contrast in initial or medial position at this stage: All her stops appeared to be voiced. For E, then, the first site of such a contrast was final position.

$6 \mathrm{D}$ also produced several words with a target voiced stop following the nasal during this period: hand, ground, land, nubberband, around, and find, all 
with final [-n]. Final [-nd] only emerged at $1 ; 11,11$ with the acquisition of sand.

7 This was probably because well established words may become frozen in a form that reflects earlier phonological organization (see Ferguson \& Farwell 1975, Macken 1979).

$8 \mathrm{Up}$ to this point, bib had always been [bI], except for one occasion when D $(1 ; 7,24)$ fluctuated all day between three different forms: [bl], [bib], and [bep]. The next day he was back at [bI], and appeared to rely on that form exclusively until he began to apply the nasal strategy.

9 The fact that such lapses were always promptly repaired to a form with the target final voiced stop suggests that $D$ was monitoring to make sure the final segments matched the target representations he had stored in memory (see further Clark 1982). Earlier, he had repaired a rare final voiceless stop to a nasal, e.g., [ $\left.r^{w} \mathrm{Dk}\right]$ to $\left[\mathrm{r}^{\mathrm{w}} \mathrm{D} \mathrm{gk}\right](1 ; 8,8)$.

$10 \mathrm{E}$ also used several words with target final [-nd] cluster during Periods 1 and 2 : hand $(1 ; 4,4$ on), band $(1 ; 4,5$ on), sand $(1 ; 5,14 / 1 ; 6,3)$, stand $(1 ; 6,3 / 1 ; 7,20)$, find $(1 ; 7,5 / 1 ; 7,6 / 1 ; 7,12 / 1 ; 8,4)$, and $k$ ind $(1 ; 8,3)$. All were consistently produced with final [n], except for one instance of hand as [ænt] $(1 ; 4,22)$, after which it reverted to [æn], and band which appeared as [bæm] $(1 ; 4,5 / 1 ; 4,18)$, with consonant harmony. The consistent uses of final $[-n]$ in these words parallels D's data for similar words.

11 A comparable instance in D's corpus occurred at $1 ; 11,28$, when $D$ had virtually abandoned the nasal strategy. Following an adult utterance containing the word muddy, D attempted it twice as [m^ni], and then a minute or two later, with no intervening adult utterance, produced [mAndi]. All D's other intervocalic voiced stops were consistently produced as voiced stops throughout the nasal strategy period.

12 Rather less explicably, E also occasionally inserted a nasal before a few target voiceless stops. E neutralized the voiced/voiceless contrast in medial position: all these stops were voiced for her. For example, she produced broken as both [bongin] and [bogin] $(1 ; 5,28)$, open as [owmbin] and [owbin] $(1 ; 7,2)$, paper as [bæmbi] $(1 ; 7,5)$, I can't as [angænt] $(1 ; 7,8)$, and chicken as [dingi] $(1 ; 7,29)$.

13 As Lass (1984) pointed out, it is common in everyday speech for a nonfinal nasal to be followed by a stop with the voicing value of the next segment, e.g., something pronounced as [s $\mathrm{mp} \theta \mathrm{I}$ ]]. This kind of consonant epenthesis also occurs in language change, e.g., OE punor > thunder (Lass, 1980).

14 However, such a characterization seems misleading if the voiceless stop children produce under these circumstances is the outcome of articulatory difficulty. See also Macken and Barton (1980).

15 This strategy should go hand in hand with the use of apparently voiceless stops for voiced targets. Whether it actually does is not well documented.

16 For some solutions to difficulties in voicing initial stops, see Macken and Barton (1980), and Allen (1985). 


\section{References}

Allen, George D. (1985) How the young French child avoids the pre-voicing problem for word-initial voiced stops. Journal of Child Language 12, 37-46.

Clark, Eve V. (1982) Language change during language acquisition. In $A d$ vances in developmental psychology, ed. by Michael E.Lamb \& Ann L. Brown, 171-195. Hillsdale, New Jersey: Lawrence Erlbaum Associates.

Dodd, Barbara (1975) Children's understanding of their own phonological forms. Quarterly Journal of Experimental Psychology 27, 165-172.

Ferguson, Charles A., \& Farwell, Carol B. (1975) Words and sounds in early language acquisition. Language 51, 419-439.

Fey, Marc E., \& Gandour, Jack (1982) Rule discovery in phonological acquisition. Journal of Child Language 9, 71-81.

Hooper, Joan B. (1977) Substantive evidence for linearity: Vowel length and nasality in English. In Papers from the thirteenth regional meeting, ed. by Woodford A. Beach, Samuel E. Fox, \& Shulamith Philosoph, 152-164. Chicago, Illinois: Chicago Linguistic Society.

Ingram, David (1975) Surface contrast in children's speech. Journal of Child Language 2, 287-292.

Kiparsky, Paul, \& Menn, Lise (1977) On the acquisition of phonology. In Language learning and thought, ed. by John Macnamara, 47-78. New York: Academic Press.

Lass, Roger (1980) On explaining language change. Cambridge: Cambridge University Press.

Lass, Roger (1984) Phonology. Cambridge: Cambridge University Press.

Maccoby, Eleanor E., \& Bee, Helen L. (1965) Some speculations concerning the lag between perceiving and performing. Child Development 36, 367-377.

Macken, Marlys A. (1979) Developmental reorganization of phonology: A hierarchy of basic units of acquisition. Lingua 49, 11-49.

Macken, Marlys M., \& Barton, David (1980) The acquisition of the voicing contrast in English: A study of voice onset time in word-initial stop consonants. Journal of Child Language 7, 41-74.

Menn, Lise (1976) Pattern, control, and contrast in beginning speech. Unpublished PhD dissertation, University of Illinois.

Slis, I.H. (1970) Articulatory measurements on voiced, voiceless, and nasal consonants. Phonetica 21, 193-210.

Smith, Bruce L. (1979) A phonetic analysis of consonantal devoicing in children's speech. Journal of Child Language 6, 19-28.

Smith, Bruce L., \& Westbury, J.R. (1975) Temporal control of voicing during occlusion in plosives. Paper presented at the 89th meeting of the Acoustical Society of America, Austin, Texas.

Smith, Neilson V. (1973) Acquisition of phonology: A case study. Cambridge: Cambridge University Press.

Velten, H. (1943) The growth of phonemic and lexical patterns in infant language. Language 19, 281-292. 


\section{Appendix 1: Data from Damon $(1 ; 8,1-1 ; 10,14)$}

Words are listed in order of production, with subsequent tokens and their forms noted according to the age at which they were observed. (All forms are listed with their original transcription from the diary record.) The emergence of adult-like production is marked with an asterisk (*) following the age (once stable, no subsequent instances are listed). Forms produced immediately after an adult production of the target word are marked by I (imitation). A capital R marks a spontaneous repair.

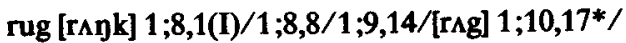

pig [pınk] $1 ; 8,1 / 1 ; 8,8 /$

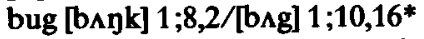

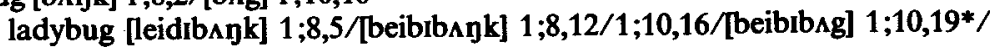
$1 ; 10,23 *$ /

bag [b^nk] 1;8,2(I)/[bænk] 1;8,9/1;8,27/1;9,1/1;9,29/[bæg] 1;10,21*/ $1 ; 11,15^{*} /$

big (earlier [bı]) [bınk] 1;8,4/1;9,14/1;9,21/[bıg] 1;10,19*/1;10,28*/

[bink-R-big] 1;10,22*/[big] 1;10,28*/1;11,4*/

[bınk-R-bıg] $1 ; 11,11 * /$ [big] $1 ; 11,16 * / 1 ; 11,18 * /$

big stick [bIn $\left.\mathrm{t}^{0} \mathrm{Ik}\right] 1 ; 8,16(\mathrm{I}) / \mathrm{big}$ ball [bink bol] $1 ; 9,25 /$

big car [bink ka] 1;9,29/big door [big do] 1;10,20*/

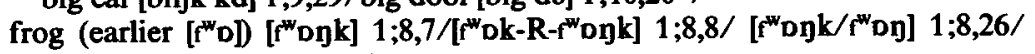
[f $\left.\mathrm{f}^{\mathrm{w}} \mathrm{og}\right] 1 ; 10,19 * / 1 ; 10,22 * /$

dog (earlier and usually [do]) [donk] $1 ; 8,11 / 1 ; 8,22 /$ dog] $1 ; 10,14 * /$

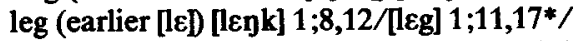

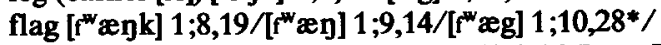

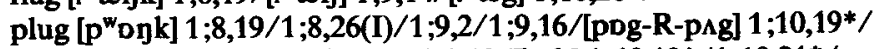

Bob (earlier [bo]) [bom/bomp] 1;8,19/[bob] 1;10,19*/1;10,21*/

bib (earlier [br], [bl/blb/beß] $1 ; 7,24)$ [bIm] $1 ; 8,21 / 1 ; 8,22 / 1 ; 9,21 / 1 ; 10,16 /[b / b]$ $1 ; 10,23 * / 1 ; 10,24 * /$

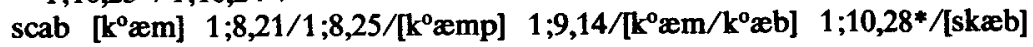
$2 ; 0,9 * /$

God [gom] 1;8,22(I)/

lid (earlier [jı1) [jim] $1 ; 8,22 /$ [jin] $1 ; 8,25 / 1 ; 9,14 /$ [lıd] $1 ; 11,8 *$ /

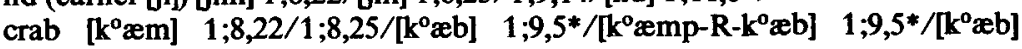
$1 ; 10,25 * /\left[\mathbf{k}^{0} æ m / \mathbf{k}^{0} æ b\right] 1 ; 10,28 * /$

sled [sjem/sєm] $1 ; 8,22 /$

bed (earlier [be]) [bem] 1;8,23/[bed] 1;10,23*/1;11,10*/

rhubarb [ruba:m] $1 ; 8,23 / 1 ; 9,28$ /

cupboard [kægum] 1;8,26/

tub [tım] $1 ; 8,26 /$

Rod [rom] $1 ; 8,29 /$

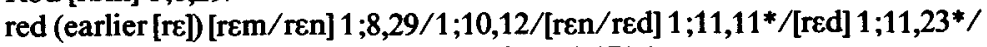

road (earlier [row]) [rowm] $1 ; 9,0 /$ [rowd] $1 ; 11,17 * /$

knob (earlier [no]) [nom] 1;9,0/

read (earlier [ri]; once [rid] (I)) [rim] 1;9,5/[ri] 1;10,9/[rid] 1;11,5*/ 
bird (earlier [b3]) [b3n] 1;9,13/[b3d] 1;10,27*/

fig [nik] 1;9,14(I)/

word [wan] $1 ; 9,14 / 1 ; 9,28(I) /$

wood [won] $1 ; 9,21 /$

ride (earlier [wai]) [waid] $1 ; 9,21 * /$

Herb (earlier [h3], always major form) [h3m] 1;9,23 (very emphatic)/1;9,25/ $1 ; 9,28 /$ hab $1 ; 10,13 * / 1 ; 10,14 * /$

head (earlier [he] [hen] 1;10,15/[hed] 1;11,6*/

showerhead [šawəhed] $1 ; 11,16 *$ /

cloud (new word) [kawd] $1 ; 10,21 * /$

outside (earlier [awtsai]) [awtsaid] $1 ; 11,4 * / 1 ; 11,5 *$ /

bread (earlier $\left.\left[b^{w} \varepsilon\right]\right)\left[b^{w} \varepsilon d\right] 1 ; 11,13^{*} /$

shutted [sıtid] $1 ; 11,13^{*} /$

$\operatorname{sad}[\mathrm{sæd}] 1 ; 11,16 *$ /

\section{Appendix 2: Data from Eva $(1 ; 5,14-1 ; 10,7$, with occasional forms to $2 ; 0,5$ )}

As in Appendix 1, the words produced are listed in order, by age, together with subsequent observations noted from daily records or from summaries made every two weeks, in their original transcriptions. Nasalized forms produced immediately after an adult utterance of the same word are marked by I (imitation). Although few nasalized forms are noted after $1 ; 10,7$, the summaries suggest they persisted in some words at least to age $2 ; 0$.

egg [ænk] $1 ; 5,14 / 1 ; 6,0-1 ; 6,14 / 1 ; 6,15-1 ; 7,0 / 1 ; 7,0-1 ; 7,14 / 1 ; 7,15-1 ; 8,0 /[æ n]$ $1 ; 8,28 / 1 ; 10,7 /$

eggs [ænks] $1 ; 6,12 / 1 ; 6,13 /$ [yæks-R-æn]) $1 ; 8,28 /$

seed (earlier [di] $1 ; 5,6$ ) [dint] $1 ; 5,15 /[$ din] $1 ; 6,9 / 1 ; 6,15-1 ; 7,0 / 1 ; 7,0-1 ; 7,14 /$

$1 ; 7,15-1 ; 8,0 /$

dog (earlier [dæ/da]) [dan] $1 ; 8,1 / 1 ; 8,4 /$

hot-dog [-dank] $1 ; 5,16 / 1 ; 5,20 /[-d æ]] 1 ; 6,28 /$

hot-dogs [dans] $1 ; 6,28 /$

frog [oy] $1 ; 5,18$ (I)/[bay] $1 ; 6,4(\mathrm{I}) /$ [bank] $1 ; 6,0-1 ; 6,14 / 1 ; 6,17 / 1 ; 7,0-1 ; 7,15 /$ $1 ; 7,15-1 ; 8,0 /$ [fan] $2 ; 0,5 /$

frogs [banks] $1 ; 6,11 / 1 ; 6,13 / 1 ; 7,0-1 ; 7,14 /$

bag (earlier [bæy] 1;5,23) [bænk] 1;5,20/[bæk-R-bæn] 1;6,4(I)/[bænk/bæn] $1 ; 6,15-1 ; 7,0 /$ [bæn] $1 ; 7,11(\mathrm{I}) /$

bean bag [binbæn] 1;6,15-1;7,0/[binbænk] 1;7,0-1;7,14/

bib (earlier [baba] 1;4,27/[biba] 1;5,8) [bim] 1;5,29(I)/[bimp] 1;6,10/[bim] $1 ; 6,18 / 1 ; 6,19 /[$ [bimp] $1 ; 7,4 / 1 ; 7,21 /$

bibs [bimps] $1 ; 6,19$ (I) $/ 1 ; 6,19 / 1 ; 10,7 /$

bed (earlier [bæ] [bæn] $1 ; 5,30 / 1 ; 6,4 /$

good [gun] $1 ; 5,30(\mathrm{I}) / 1 ; 6,0-1 ; 6,14 / 1 ; 6,10 / 1 ; 7,0-1 ; 7,14 /$ [gunt] $1 ; 7,23$ (I)/[gun] $1 ; 10,7 /$ 
bead (earlier [bi], [bi:t] $1 ; 4,23 / 1 ; 5,8 / 1 ; 5,9)$ [bin] $1 ; 6,0-1 ; 6,14 / 1 ; 6,15-1 ; 7,0 /$

$1 ; 7,0-1 ; 7,14 /[$ bi:n] $1 ; 8,27 /$ [bi:t] $1 ; 8,27 /$ [bin] $1 ; 10,7 /$

beads [bins] $1 ; 6,11 / 1 ; 6,19 / 1 ; 8,16 / 1 ; 8,27 / 1 ; 8,28 /$

pig [bink] $1 ; 6,4(\mathrm{I}) /$ /bin] $1 ; 8,25 /$

food [bun] $1 ; 6,5$ (I)/[fun] $1 ; 10,7 /$

slide (earlier [dæy] $1 ; 5,1 / 1 ; 6,0-1 ; 6,15)$ [dayn] $1 ; 6,15-1 ; 7,0 /$ ddaynts] $1 ; 7,0 /$ [dayn] 1;8,4/

mad [mæ:n] 1;6,18(I)/

did [din] $1 ; 6,21(\mathrm{I})) /[\operatorname{dint}] 1 ; 7,8(\mathrm{I}) /[\operatorname{din}] 1 ; 10,22 /[\operatorname{dint}] 1 ; 10,27 /$

kids [gins] $1 ; 6,27 / 1 ; 7,0-1 ; 7,15 / 1 ; 7,15-1 ; 8,0 /$ [gIts] $1 ; 8,28 /$

Brad [bæn] 1;6,28/1;7,29/1;8,27/

outside [dayn] $1 ; 6,29 / 1 ; 7,17 /$ [awtdayn] $1 ; 8,27 /$ [awtsayn] $1 ; 10,27 /$

dead [dænt] $1 ; 7,0(I) /$

big (lbik] 1;5,14/1;5,15) [bink] 1;7,2(I)/[bin] 1;7,5/[bink] 1;7,9/[bin] 1;7,12/

[bin/bink] 1;7,29(I)/[bin] 1;8,0/[bink] 1;8,17/[bik] 1;9,5/

Big Bird [bin bun] 1;8,7/[bin bun] 1;8,17/[bin bun] 1;8,28/

big horsie [bin owsi] $1 ; 8,16 /$ big bear [bin be] 1;8,17/

washrag [abæn] $1 ; 7,6(\mathrm{I})$ /

leg [læn] 1;7,6(I)/

legs [æyks] $1 ; 8,18(\mathrm{I}) / 1 ; 8,19 / 1 ; 10,17 /$

bread (earlier [byæ] $1 ; 4,19)$ [bæn] $1 ; 7,6(1) / 1 ; 7,8 / 1 ; 7,15-1 ; 8,0 /$

ride [wayn] $1 ; 7,15 / 1 ; 7,23 / 1 ; 8,1 / 1 ; 8,16 / 1 ; 8,23 /$

Bob [bamp] $1 ; 7,16 /$

hide [ayn] $1 ; 7,18(\mathrm{I}) / 1 ; 8,19 /$

read [min] $1 ; 7,18 /[$ win] $1 ; 8,18 / 1 ; 8,28 / 1 ; 9,15 /$

hard [ayn] $1 ; 7,23(\mathrm{I}) / 1 ; 7,24 /$

need [nin] $1 ; 8,1 /[$ nint] $1 ; 10,7 /$

hold [own] $1 ; 8,4 / 1 ; 8,7 /$ [ayn] $1 ; 8,21(\mathrm{I}) /$

bird (earlier [bi] 1;3,2/1;4,15/1;4,19) (Big) Bird [bun] 1;8,7/1;8,17/1;8,28/

Hoag (name [hoigl) [oink] 1;9,27(I)/

head [æn] $1 ; 10,6 /$

bad [bæn] 1;10,7/

crib [kimp] 1;10,7/

hood [u:n] $1 ; 10,7 /$

red [rent] 1;10,22(I)/

Richard [witsun] 1;10,26/ 